\title{
EOQ FOR PERISHABLE GOODS: MODIFICATION OF WILSON'S MODEL FOR FOOD RETAILERS
}

\author{
Shouzhen ZENG $^{1}$, Oleksandr NESTORENKO ${ }^{2}$, Tetyana NESTORENKO ${ }^{3}$, \\ Mangirdas MORKŪNAS ${ }^{4}$, Artiom VOLKOV ${ }^{5}$, Tomas BALEŽENTIS ${ }^{5}$, \\ Chonghui $\mathrm{ZHANG}^{6^{*}}$, \\ ${ }^{1}$ School of Business, Ningbo University, 315211 Ningbo, China \\ ${ }^{2}$ Faculty of National Economy, University of Economics in Bratislava, \\ Dolnozemska cesta 1, 85235 Bratislava, Slovak Republic \\ ${ }^{3}$ Department of Economics, Entrepreneurship and Finance, Faculty of the Humanities and Economics, \\ Berdyansk State Pedagogical University, 4 Shmidt Str., 71112 Berdyansk, Ukraine \\ ${ }^{4}$ Faculty of Economics and Business, Mykolas Romeris University, \\ Ateities g. 20, 08303 Vilnius, Lithuania \\ ${ }^{5}$ Lithuanian Institute of Agrarian Economics, Kudirkos g. 18-2, 03105 Vilnius, Lithuania \\ ${ }^{6}$ College of Statistics and Mathematics, Zhejiang Gongshang University, 310018 Hangzhou, China
}

Received 15 May 2019; accepted 17 August 2019

\begin{abstract}
A timely response to a fluctuating and ever-changing consumer demand is an important decision for a company, as it may impact its position in the market. Thus, proper inventory management becomes a focal point in retail business process management and can provide a substantial competitive advantage. In this paper, we introduce a modified version of Wilson's model, which takes into account trends in consumer demand and offer flexibility in reordering time. The illustration of the proposed model is presented, showing the significant economic benefit under particular conditions.
\end{abstract}

Keywords: economic order quantity, Wilson's model, inventory management, retail.

JEL Classification: C13, L23, M11.

\section{Introduction}

Ongoing concentration in food retail business show increasing competition levels among biggest market players, due to more equal market shares (Aguirregabiria \& Vicentini, 2016; Hosken, Olson, \& Smith, 2018), not allowing to employ profit generation mechanisms often associated with dominance in market power. This forces companies to be more flexible in adapting their strategies directing them in a search for even low term and easily repeatable

*Corresponding author. E-mail: zhangch1988@zjgsu.edu.cn

This is an Open Access article distributed under the terms of the Creative Commons Attribution License (http://creativecommons. org/licenses/by/4.0/), which permits unrestricted use, distribution, and reproduction in any medium, provided the original author and source are credited. 
competitive advantages to confront the competitors and maintain market position. As retail business is being characterized by quite low profit margins, diminishing possibilities of a price competition, a new ways of gaining a competitive advantage are being required. One of effective methods to increase profitability and gain a competitive advantage is to lower the costs, associated with supply chain management. It is assumed, that company can have the biggest impact onto its own inventory management system, and the financial effect from the actions, aimed at freeing financial capital locked in supply activities can be felt there (Quesada-Pineda, 2008), as retailer's influence onto other partners in supply chain can vary from quite significant, to marginal (Ganesan, George, Jap, Palmatier, \& Weitz, 2009). Even at the macro level, the advanced supply chain modelling approaches have been considered (Song, Cui, \& Wang, 2018; Yao, Huang, Song, \& Mishra, 2018).

The substantial financial effect of modifications in retailer's inventory management can be achieved only if inventory levels are systematically lowered (Tasdemir \& Hiziroglu, 2019), as retailer maintains an everyday supply procedures. It makes the proper management of the supply chain, especially its part between warehouse and store shelf more critical than it was before (Myerson, 2012). Coupled with constant shifts in consumer preferences, making demand forecasting more complex, providing procurement managers of retail chains challenges, which overcoming require a sophisticate inventory management models, providing possibility of a simultaneous demand and procurement handling.

The conventional models for inventory management with uncertain demand, such as variations of Harris (1913) formulation (Cárdenas-Barrón, Chung, \& Treviño-Garza, 2014; Nobil \& Taleizadeh, 2016; Budd \& Taylor, 2019), Markov equation based ones (Boute, Disney, Lambrecht, \& Van Houdt, 2007; Broyles, Cochran, \& Montgomery, 2010; Liu, Feng, \& Wong, 2014), Wilson's formulation (Wilson, 1934; Schwartz, Wang, \& Rivera, 2006; Sarkar, 2013; Manna, Dey, \& Mondal, 2017) are designed to minimize the expected costs of replenishment and stockouts, assuming, that complete satisfaction of uncertain and hardly predictable demand is too expensive or even deemed impossible. All these models are design under the constant order quantity principle, where the size of following order is based on the objective to minimize the whole costs of company's inventory management. A large number of various modifications have been introduced with different levels of backup inventory, replenishment time, increased checkout points and etc., although not implemented into practice, as most of inventory systems, especially ones related to retail, possess complications that require a new variations of existing inventory management models, what are capable of handling specific retail problems in ever-changing day to day situations. This deficiency and discrepancy to practical use attract scientific critics (Dubelaar, Chow, \& Larson, 2001; Fleisch \& Tellkamp, 2005; Bendoly, Craig, \& DeHoratius, 2018) to the existing inventory management models in retail, as complete and timely response to changes in consumer demand is being considered as one of main competitive advantages of food retailers (Fernie \& Sparks, 2018). Other challenge, faced by food retailers is a perishable nature of its inventory compared to manufactured goods. A short expiry date of a food retailers goods, unpredictable and constantly changing demand, affecting the size and frequency of orders lead to a situation, there classical inventory management models become unsuitable for solving practical inventory management problems, thus motivating a search of a new modified alternatives, so the aim of this research paper is to modify the existing Wilson's formulation to fit the needs of food retailers. 


\section{Literature review}

Business decisions require accounting for various factors in order to ensure sustainability (Yuan \& Zhang, 2017; Rostamzadeh, Esmaeili, Shahriyari Nia, Saparauskas, \& Keshavarz Ghorabaee, 2017; Feng, Zhao, Jia, \& Shao, 2019). A wide range of models were proposed for an efficient inventory management since 1913, then Harris introduced Economic Order Quantity concept to the World. As proposed in a form of static formula, Harris model and all its deviations are being called static inventory management models. Typical static EOQ models (De Matteis \& Mendoza, 1968; Silver \& Meal, 1973; Wahab, Mamum, Ongkunaruk, 2011) do not satisfy retail practitioners because of their inability to react to changing consumer demand, requiring the same order quantity in equal periods of time (Sterligova, 2005). Recent years show increased scientific interest in solving this problem. Sana (2011) proposed an EOQ model for perishable goods, which dynamics is being determined by reaction to retail price sensitiveness. Although it's practical implementation is restricted by the fact, that it does not take into account the minimizing effect of negative power function of price, which induces a high rate of change in consumer demand. These new steps in EOQ model development motivate us to formulate an econometric model, a Wilson's model deviation, which would cover also varying amount of order and different ordering periods. There have been attempts to solve this problem using Markovian formulations (Yin, Liu, \& Johnson, 2002; Isotupa, 2006; Beyer, Cheng, Sethi, \& Taksar, 2010; Minoux, 2018). Although they succeed in optimizing inventory costs, most of them created models, which require quite a precise demand forecasting in order to achieve a satisfactory inventory management levels. We deem it impossible in retail business, as like most of processes in a real world, a demand dynamic variation, showing seasonal, occasional and spot shocks may be considered stochastic, unsuitable for forecasting by typical probabilistic models. Plus, if retailer experienced shortages of products or other mismatches with inventory management, before it is likely affect demand in the future, as some customers may not lay their all confidence on this retailer expecting possible now shortages in assortment, thus making future demand forecasting even more complicated.

Proper management of logistics operations is crucial to the success of food retailing (Gustafsson, Jönson, Smith, \& Sparks, 2006). It can either create a substantial competitive advantage (Chen, Wang, \& Chan, 2017) or even lead to insolvency (Durach \& Nitsche, 2016). The deficiencies in logistics processes are even considered one of the main barriers for developments in retailing industry as a whole (Goldman, Ramaswami, \& Krider, 2002). Hackl, Scharitzer, and Zuba (2000) found, that one of the determinants of customer satisfaction in food retailers is a wide assortment of fresh products. It creates additional challenges for food retailers' logistics departments, as they face a duopoly between high costs and flexibility (Soto-Silva, Nadal-Roig, González-Araya, \& Pla-Aragones, 2016). Although there were attempts to adjust existing supply quantity management models to meet this issue (Rong, Akkerman, \& Grunow, 2011), these models are struggling when facing another high challenge of food retailers - ever changing consumer demand (Ortega, Wang, Wu, \& Hong, 2015). Its characteristics, such as variations in preferences (Hinsley, Verissimo, \& Roberts, 2015; Hayakawa \& Vieneris, 2016), unequal consumption (Crist, Mora, \& Engelman, 2017), added im- 
plicit characteristics to existing products (Greenstone, 2017) create unique challenges for lot managers in calculating the optimal economic order quantity for various food retail stores.

The EOQ adjustments can be based on a supply disruptions problem (Taleizadeh, 2017; Paul, Sarker, \& Essam, 2018) taking into assumption, what demand is of a random nature, the supply process can be affected by both exogenous and endogenous perturbations and only retailer's inner inventory management can be attributed to discrete time stochastic processes (Konstantaras, Skouri, \& Lagodimos, 2019). We argue this scientific view, at least in retail business, as typically retailers have a wide range of competing vendors and can easily switch from one to another (Wagner \& Benoit, 2015) thus lowering the uncertainty in a supply chain.

The economic costs of inventory management can be a decisive factor. One of the first authors in this field - Schwartz (1970) has introduced an optimal order point and quantity determination models for a single company stressing different scenarios where for different reasons unfulfilled existing demand can be satisfied at any point latter, thus not compromising company's financial results in a long run, also scenarios of unperformed sales and its economic costs. Liberopoulos, Tsikis, and Delikouras (2010) researching stockout costs enriched Schwartz findings with economical substantiation of backorder costs proposing new model for computation of an optimal EOQ. Potential cost savings is a focus point of Tasdemir and Hiziroglu (2019) research. Although their proposed raw materials inventory model under certain circumstances could increase cost savings optimizing storage quantities not compromising a predefined customer satisfaction level, it is applicable only to production companies using a bulk unpacked raw materials, especially those, which are dependent on one type of raw materials and act as intermediaries in a relatively low value added creation process by only slightly changing particular products shape. A modified version of EOQ assessment for manufacturing companies has been presented by De and Sana (2014). Although it combines features of both Economic Production Quantity (EPQ) and Economic Order Quantity (EOQ) formulas, thus creating an elegant framework for creation of a quite precise production process planning model, it is still design and applicable only to manufacturing companies and lacks the flexibility required by retailers, especially those dealing with perishable goods. This scientific view is being supported by Tamjidzad and Mirmohammadi (2017) showing unavoidable incremental quantity discount arising due to a stochastic nature of retailing demand.

Economic literature focuses not only on EOQ in the context of inventory management in retail. Khmelnitsky and Singer (2015) show improper inventory management effect onto retailer's reputation stressing inventory management focal point in increasing reputation based demand. Karimi, Ghomi, and Wilson (2003) modified a Wilson's formulation in order to determine the optimal lot size for production companies taking into account the deterioration of items. Although close to our task, this researched is based on one size lot type, acceptable for production companies, but not very suitable for retailers. Battini, Persona, and Sgarbossa (2014) modify the classical static Harris, Naim, Palmer, Potter, and Mumford (2011) inventory management model applying "prudent approach" in order to balance the environmental issues in calculating the most efficient way of transporting goods into the warehouse. Although a new approach in logistics, accepting environmental sustainability 
costs as an "external costs" (Ortolani, Persona, \& Sgarbossa, 2011), focuses more on the choice of transport mode, but not on the inventory management, so it is more suitable for wholesale companies compared to retailers. Generalizing the literature review we found, that scientific literature has a vacuum in inventory management models, which take into account changes in consumer demand and offer flexibility in reordering time, thus allowing them to be more widely used in food retailing.

\section{Formulation of the model}

The theoretical model of inventory management (economic order quantity (EOQ) model) is widely used in logistics. Given the relationship between the material and financial flows of warehouse logistics, the model created in 1934 by R. Wilson allows determining the optimal order quantity $\left(q_{W}\right)$, the optimal time between orders $\left(t_{S W}\right)$ at which the total cost of purchasing and storing goods $(T C)$ during the planning period $(T)$ are minimal. Wilson's model presented in formula 1 :

$$
\operatorname{TC}(q)=\frac{c_{S} D}{q}+\frac{1}{2} c_{1} T q \rightarrow \min .
$$

The optimal solution of Wilson's model:

$$
\begin{gathered}
q_{W}=\sqrt{\frac{2 c_{S} D}{c_{1} T}} ; \\
t_{S W}=\frac{q_{W}}{\mu}=\sqrt{\frac{2 c_{S} T}{c_{1} D}},
\end{gathered}
$$

where: $c_{S}$ is the cost of delivery, $D$ is the demand for time horizon $T, c_{1}$ is the cost of storing a unit of goods per day, $\mu$ is the daily demand.

Taking into account Slesarenko and Nestorenko (2014) and O. Nestorenko, Péliová, and T. Nestorenko (2017) remarks to the construction of Wilson's model, the basic model of inventory management is:

$$
\operatorname{TC}\left(t_{S}\right)=\left(c_{S}+p \mu t_{S}\right) \frac{(1+r)^{t_{S}}\left((1+r)^{T}-1\right)}{(1+r)^{t_{S}}-1}-\frac{p \mu\left((1+r)^{T}-1\right)}{\ln (1+r)} \rightarrow \text { min, }
$$

where $p$ is the purchase price, $r$ is the interest rate per day.

Let us denote $z=\ln (1+r) t_{S}, z_{W}=\ln (1+r) t_{S W}, Z=\ln (1+r) T$. Then:

$$
T C(z)=\frac{p \mu\left(E^{Z}-1\right)}{\ln (1+r)}\left(\left(\frac{1}{2} z_{W}^{2}+z\right) \frac{E^{z}}{E^{z}-1}-1\right) \rightarrow \min ,
$$

where $y=E^{Z}$ is an exponential function.

Function (5) reaches its minimum at the solution of a nonlinear equation:

$$
E^{z}=1+z+\frac{1}{2} z_{W}^{2}
$$

The approximate value of the solution obtained by decomposing the function $E^{z}$ in the Maclaurin series (Beyer, 1987) up to the second degree coincides with the Wilson's optimum: 


$$
t_{S 0}=t_{S W}=\sqrt{\frac{2 c_{S}}{r p \mu}} .
$$

The changes in stocks in this case are shown in Figure 1.

Models (1)-(3) and (4)-(7) were built under the restrictive assumption of equal time between orders $\left(t_{S i}=t_{S}, i=\overline{1, n}\right)$, where $n$ is the number of orders during time horizon $T$. Since daily demand is constant, the quantity of orders is also equal $\left(q_{i}=q, i=\overline{1, n}\right)$. We construct a model without these restrictions. First, we build a model with a fixed number of orders during $T$ :

or

$$
T C\left(t_{S i}\right)=\sum_{i=1}^{n}\left(c_{S}+p \mu t_{S i}\right)(1+r)^{T-\sum_{j=1}^{i-1} t_{S j}} \rightarrow \min
$$

$$
T C\left(z_{i}\right)=\frac{p \mu}{\ln (1+r)} \sum_{i=1}^{n}\left(\frac{1}{2} z_{W}^{2}+z_{i}\right) E^{Z-\sum_{j=1}^{i-1} z_{i}} \rightarrow \min .
$$

The optimal solution $z_{0}=\left(z_{01}, z_{02}, \ldots, z_{0 n}\right)$ is obtained by solving a system of nonlinear equations:

$$
\left\{\begin{array}{c}
E^{z_{i}}=\frac{1}{2} z_{W}^{2}+1+z_{i+1}, i=\overline{1, n-1} \\
\sum_{i=1}^{n} z_{i}=Z
\end{array} .\right.
$$

Solving the system (10) by decomposition of functions $E^{z}$ and $\sqrt{1+z}$ into Maclaurin's series to the second degree, we obtain different versions of the approximate optimal solution:

$$
\begin{gathered}
z_{0 i}=z_{W}+\frac{\left(\frac{Z}{n}-z_{W}\right)}{1+\frac{1}{2} z_{W}(n-1)}\left(1+(i-1) z_{W}\right) ; \\
z_{0 i}=\frac{Z}{n}+\frac{1}{2}\left(\frac{1}{2}(n+1)-i\right)\left(z_{W}^{2}-\frac{Z^{2}}{n^{2}}\right) ; \\
z_{0 i}=z_{W}+\left(Z-n z_{W}\right) \frac{E^{z_{w}}-1}{E^{n z_{w}}-1} E^{(i-1) z_{w}}
\end{gathered}
$$

In this case, the minimum costs will be equal to:

$$
T C_{0}=\frac{p \mu}{\ln (1+r)}\left(\left(\frac{1}{2} z_{W}^{2}+1+z_{01}\right) E^{Z}-E^{z_{0 n}}\right) .
$$

If the number of orders $n$ in time horizon $T$ is lower than the optimal quantity of orders $n_{0}=\frac{T}{t_{S 0}}$ as it is in model (4)-(7), the time between subsequent orders increases, i.e. $t_{S 01}<t_{S 02}<\ldots<t_{S 0 n}$ (Figure 2). Otherwise, the time between subsequent orders decreases (Figure 3). 


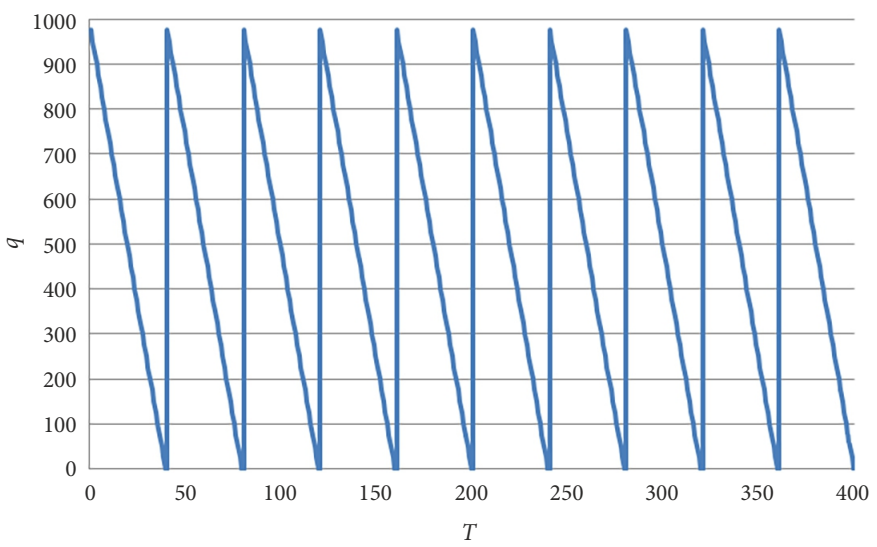

Figure 1. Dynamics in stock level $q$ assuming varying order quantities $n_{0}$ and time (source: compiled by the authors)

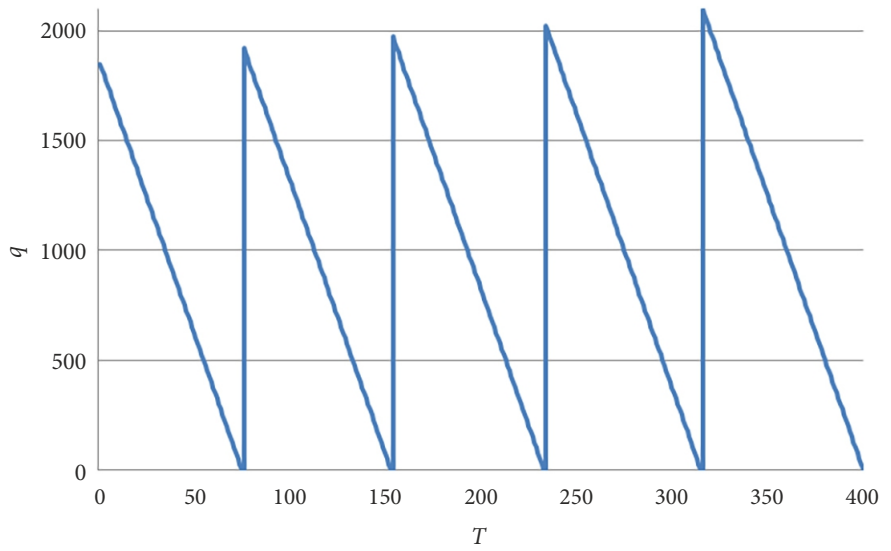

Figure 2. Dynamics in stock level $q$ assuming varying order quantities $n$ and time between orders $t_{S i}$ ( $n<n_{0}$ orders per time $T$ ) (source: compiled by the authors)

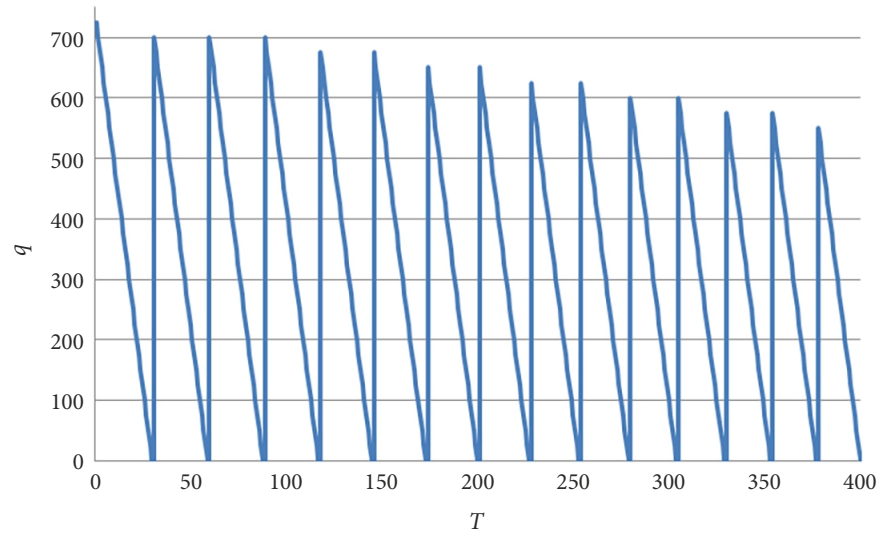

Figure 3. Dynamics in stock level $q$ assuming varying order quantities $n$ and time between orders $t_{S i}$ orders per time $T$ ) (source: compiled by the authors) 
Thus we determine the quantity of orders for time horizon $T$, for which the total cost in (14) will reach the minimum value as:

$$
T C_{0}=\frac{p \mu}{\ln (1+r)}\left(\left(\frac{1}{2} z_{W}^{2}+1+z_{01}\right) E^{Z}-E^{z_{0 n}}\right) \rightarrow \min .
$$

Then, we find the derivative of the function (14) and equate it to zero:

$$
\frac{d T C_{0}(n)}{d n}=\frac{p \mu}{\ln (1+r)}\left(\frac{d z_{01}(n)}{d n} E^{Z}-\frac{d z_{0 n}(n)}{d n} E^{z_{0 n}}\right)=0 .
$$

According to (13), if $i=1$ and $i=n$, we obtain the equality:

$$
z_{0 n}=z_{W}+\left(z_{01}-z_{W}\right) E^{(n-1) z_{w}} .
$$

Then, we find the derivative of (16) and substitute into Equation (15):

$$
\frac{p \mu}{\ln (1+r)}\left(\frac{d z_{01}(n)}{d n} E^{(n-1) z_{w}}\left(E^{z_{w}}-E^{z_{0 n}}\right)-\left(z_{01}-z_{W}\right) z_{w} E^{(n-1) z_{w}+z_{0 n}}\right)=0 .
$$

Equality in (17) will be satisfied when $z_{01}=z_{0 n}=z_{w}$. Therefore, taking into account (10), the total costs function (14) reaches its minimum when $z_{0 i}=z_{w}, i=\overline{1, n_{0}}$, and if $n_{0}=\frac{T}{t_{w}}$. Thus, in the model (4)-(7) it is possible to remove the condition (limitation) of equality of time between orders, since the function of total costs (4) reaches its minimum precisely when the time between orders is constant.

Models (1)-(3) and (4)-(7) were built under the restrictive assumption of the constant daily demand ( $\mu=$ const). We overcome this restriction by assuming that daily demand follows a linear trend $(\vartheta(t)=\mu+\omega(t-1), t \in(1, T))$ during planning time $T$. First, we build a model with a constant time between orders $\left(t_{S i}=t_{S}, i=\overline{1, n}\right)$, where $n$ is the number of orders for the time horizon $T$. The total cost function for this model will be:

$$
T C\left(t_{S}\right)=\sum_{i=1}^{n}\left(c_{S}+p\left(\left(\mu-\frac{1}{2} \omega\right) t_{S}+\frac{1}{2} \omega t_{S}^{2}\right)+(i-1) p \omega t_{S}^{2}\right)(1+r)^{(n-i+1) t_{S}} .
$$

After transformations, (18) becomes:

$$
\begin{aligned}
& \operatorname{TC}(z)=\frac{p \mu\left(E^{Z}-1\right)}{\ln (1+r)}\left(\frac{1}{2} z_{W}^{2}+\left(1-\frac{1}{2} \frac{\omega}{\mu}\right) z+\frac{1}{2} \frac{\omega}{\mu \ln (1+r)} z^{2}\right) \frac{E^{z}}{E^{z}-1}- \\
& \frac{p \omega\left(E^{Z}-1\right)}{(\ln (1+r))^{2}} z^{2} \frac{E^{z}}{\left(E^{z}-1\right)^{2}}+\frac{p \omega T}{\ln (1+r)} z \frac{E^{z}}{E^{z}-1} .
\end{aligned}
$$

Using the expansion of the function $E^{z}$ in the Maclaurin series to the second degree, we obtain the value of the approximate optimal solution:

$$
t_{S 0}=\sqrt{\frac{\mu}{\mu+\frac{1}{2} \omega(T-1)}} t_{S W} .
$$

Given the form of $t_{S W}$ in (3), we obtain the value of the optimal time between orders is: 


$$
t_{S 0}=\sqrt{\frac{2 c_{S}}{r p\left(\mu+\frac{1}{2} \omega(T-1)\right)}} .
$$

The optimal time between orders for a demand-driven model that has a linear trend differs from the optimal time between orders for a model with constant demand (average demand) per time horizon $T$. In (3), it was equal to the daily demand $\mu$, in our case (20b) it is expressed as $\mu+\frac{1}{2} \omega(T-1)$.

The optimal order quantities are as follows:

$$
q_{0 i}=\left(\mu-\frac{1}{2} \omega\right) t_{S 0}+\frac{1}{2} \omega t_{S 0}^{2}+(i-1) \omega t_{S 0}^{2}, i=\overline{1, n} .
$$

The dynamics in stocks under model (18)-(21) in the case of an increasing and decreasing linear trends of daily demand under constant time between orders is shown in Figures 4 and 5 respectively.

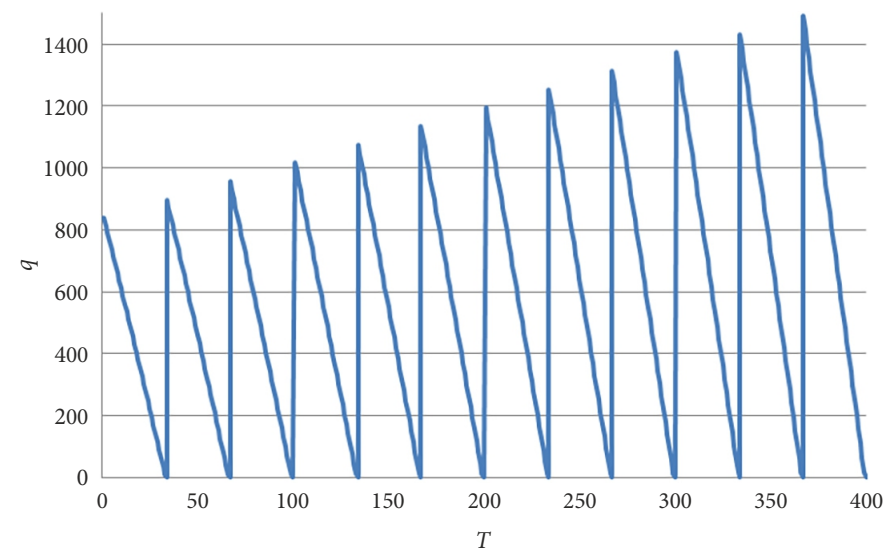

Figure 4. Dynamics in stock levels $q$ in the case of an increasing linear trend of daily demand under and constant time between orders $t_{S 0}$ (source: compiled by the authors)

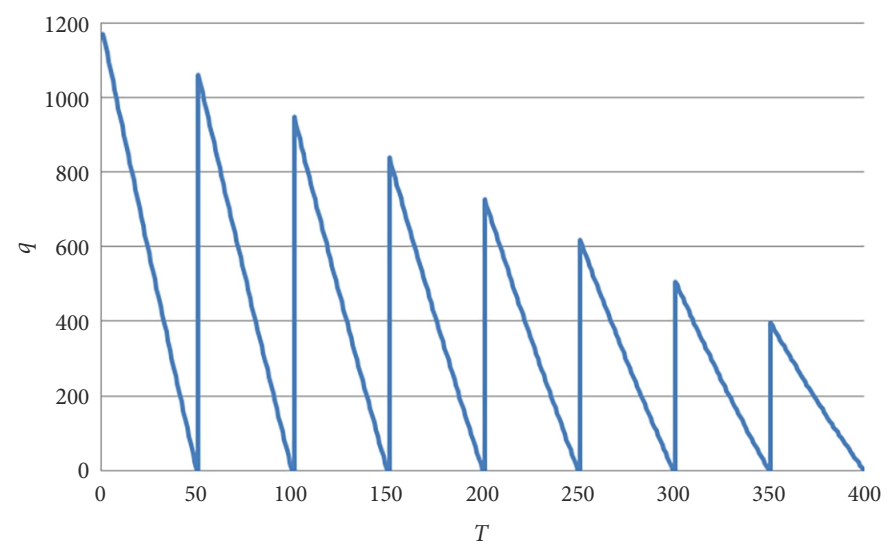

Figure 5. Dynamics in stock levels $q$ in the case of a decreasing linear trend and constant time between orders $t_{S 0}$ (source: compiled by the authors) 
Thereafter, we build a model with a constant order quantity $\left(q_{i}=q, i=\overline{1, n}\right)$, where $n$ is the number of orders for the time horizon $T$. The function of total costs for this model will be:

$$
\begin{gathered}
\operatorname{TC}(q)=\left(c_{S}+p q\right) \sum_{i=0}^{n-1}(1+r)^{T-T_{i}} ; \\
T_{i}=\frac{\sqrt{\left(\mu-\frac{1}{2} \omega\right)^{2}+2 i \omega q-\left(\mu-\frac{1}{2} \omega\right)} .}{\omega} .
\end{gathered}
$$

After transformations (22 and 23) will be as:

$$
\begin{gathered}
T C(z)=\frac{p\left(\mu-\frac{1}{2} \omega\right)}{\ln (1+r)}\left(\frac{1}{2} z_{W}^{2}+z\right) \sum_{i=0}^{n-1} E^{Z-Z_{i}} ; \\
Z_{i}=\frac{\sqrt{1+2 i \theta z}-1}{\theta},
\end{gathered}
$$

where $\theta=\frac{\omega}{\ln (1+r)\left(\mu-\frac{1}{2} \omega\right)}$.

Using the expansion of the functions $E^{z}$ and $\sqrt{1+z}$ in Maclaurin series to the second degree, we obtain the value of the approximate optimal solution:

$$
\begin{gathered}
q_{0}=\sqrt{\frac{\mu+\frac{1}{2} \omega(T-1)}{\mu} q_{W} ;} \\
q_{0}=\sqrt{\frac{2 c_{S}\left(\mu+\frac{1}{2} \omega(T-1)\right)}{r p} .} .
\end{gathered}
$$

The optimal time between orders is determined by the formula:

$$
t_{S 0 i}=\frac{\sqrt{\left(\mu-\frac{1}{2} \omega\right)^{2}+2 i \omega q_{0}}-\sqrt{\left(\mu-\frac{1}{2} \omega\right)^{2}+2(i-1) \omega q_{0}}}{\omega}, i=\overline{1, n} .
$$

The optimal order quantity for a model with demand that has a linear trend differs from the optimal order quantity for a model with constant demand (average demand) per time horizon $T$. In (2) it was equal to the daily demand $\mu$, in (27) it is equal to demand $\mu+\frac{1}{2} \omega(T-1)$.

The dynamics in stocks in the model (22)-(28) in the case of an increasing and decreasing linear trend of daily demand under the condition of a constant order quantity is shown in Figures 6 and 7. 


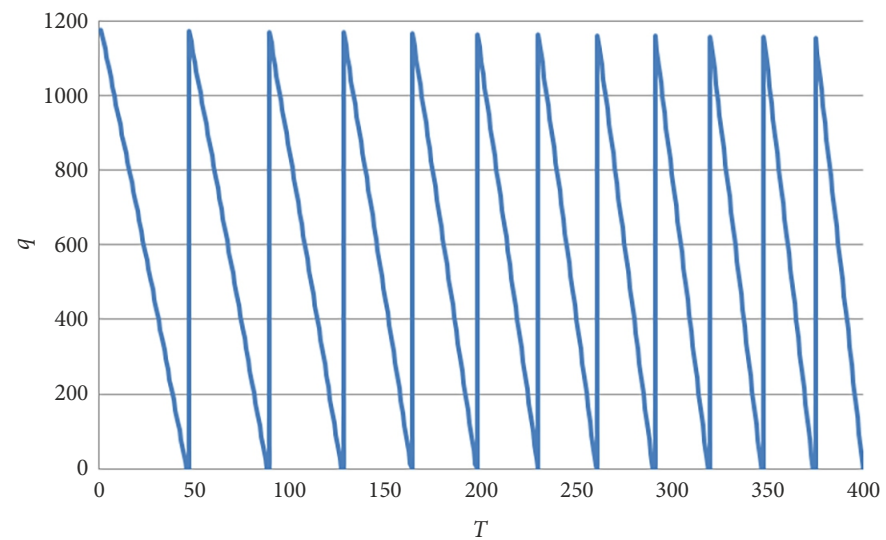

Figure 6. Dynamics in stock levels $q$ in the case of an increasing linear trend of daily demand and constant order quantity $q_{0}$ (source: compiled by the authors)

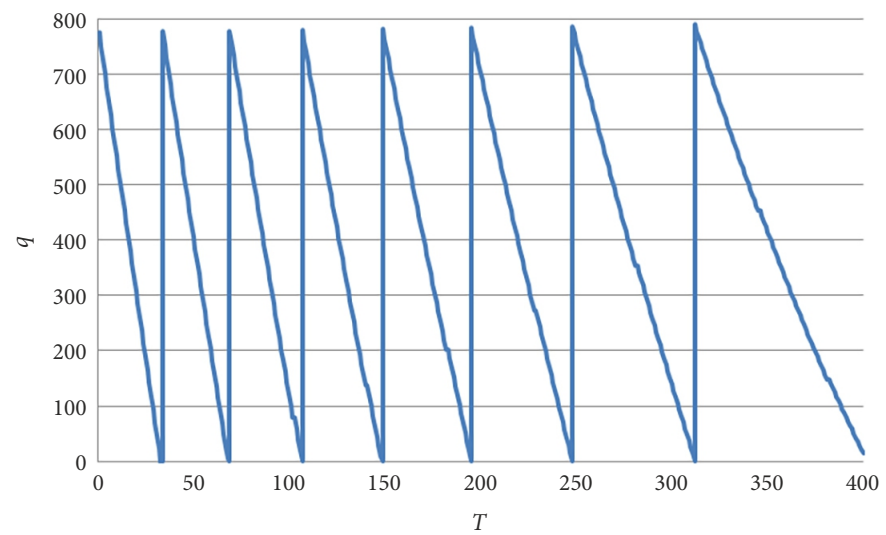

Figure 7. Dynamics in stock levels $q$ in the case of a decreasing linear trend and constant order quantity $q_{0}$ (source: compiled by the authors)

Finally, can build a model with a fixed number of orders $(n)$ during $T$. The total cost function for this model will be:

$T C\left(t_{1}, t_{2}, \ldots, t_{n}\right)=\sum_{i=1}^{n}\left(c_{S}+p\left(\mu-\frac{1}{2} \omega+\omega\left(t_{1}+t_{2}+\ldots+t_{i-1}\right)+\frac{1}{2} \omega t_{i}\right) t_{i}\right) \star(1+r)^{T-\left(t_{1}+t_{2}+\ldots+t_{i-1}\right)}$.

After transformation, (29) becomes:

$\operatorname{TC}\left(z_{1}, z_{2}, \ldots, z_{n}\right)=\frac{p\left(\mu-\frac{1}{2} \omega\right)}{\ln (1+r)} \sum_{i=1}^{n}\left(\frac{1}{2} z_{W}^{2}+\left(1+\theta\left(z_{1}+z_{2}+\ldots+z_{i-1}\right)+\frac{1}{2} \theta z_{i}\right) z_{i}\right) * E^{Z-\left(z_{1}+z_{2}+\ldots+z_{i-1}\right)}$,

where $\theta=\frac{\omega}{\ln (1+r)\left(\mu-\frac{1}{2} \omega\right)}$. 
The total cost function (30) reaches its minimum in solving a system of nonlinear equations (31):

$$
\left\{\begin{array}{c}
\left(1+\theta\left(z_{1}+z_{2}+\ldots+z_{i}\right)\left(E^{\left.z_{i}-1\right)}=\frac{1}{2} z_{0}^{2}+\left(1+\theta\left(z_{1}+z_{2}+\ldots+z_{i}\right)\right) z_{i+1}+\frac{1}{2} \theta z_{i+1}^{2}, i=\overline{1, n-1}\right.\right. \\
\sum_{i=1}^{n} z_{i}=Z
\end{array} .\right.
$$

The solution of the system of nonlinear equations (31) can be found by iterative methods. We could not find an approximate solution of the system (31) in an analytical form, since the optimal number of orders in the models (22)-(28), (18)-(21) is the same:

$$
n_{0}=\frac{D}{q_{0}}=\frac{\left(\mu+\frac{1}{2} \omega(T-1)\right) T}{\sqrt{\frac{2 c_{S}\left(\mu+\frac{1}{2} \omega(T-1)\right)}{r p}}}=\frac{T}{\sqrt{\frac{2 c_{S}}{r p\left(\mu+\frac{1}{2} \omega(T-1)\right)}}}=\frac{T}{t_{S 0}} .
$$

Considering the conclusion about the optimal number of orders in the model (15)-(17), we can assume that the optimal number of orders in the model (29)-(31) will also be equal to the optimal number from (32) and the minimum total costs will coincide with the optimal costs from the models (22)-(28) and (18)-(21). Therefore, in practice, when managing inventories in the case of daily demand with a trend, it is more convenient to use a model with a constant time between orders or a constant order quantity.

\section{Empirical application of the modified Wilson's model}

The use of the inventory management model with the trend as given by (22) has its positive and negative sides. The negative one is the need to collect and analyze additional information and builds a predictable trend of demand change on the planning period T. Positive one is getting a fixed logistics plan for the entire period $T$ as in (27), (28) and Figures 6 and 7 along with optimal (minimum) costs. If the model (18) is abandoned, there are two main options for making a decision: apply EOQ model at the beginning of period $T$ or apply model at the beginning of each "delivery-storage" cycle. Application of the EOQ model at the beginning of period T starts with calculation of the fixed order quantity $q_{W}$ using the Wilson formula (2) with a known initial daily demand amount $\mu_{0}$ and bringing the goods as inventory depletes through the actual time $t_{S i}$. This leads to an increase in total.

Figure 8 shows dynamics of movement of goods in stock according to model (22) in the case of an increasing linear trend of daily demand under the condition of a constant order quantity $q_{W}$ (determined by the Wilson model (2)) and $q_{t r}$ (the optimal value in models with the trend (27)).

In the case of a decreasing linear trend of daily demand under the condition of a constant order quantity $q_{W}$, determined by the Wilson model (Eq. (2)) and $q_{t r}$, the optimal value in models with the trend (Eq. (27)) dynamics of movement of goods in stock according to Eq. (22) are shown in Figure 9. 


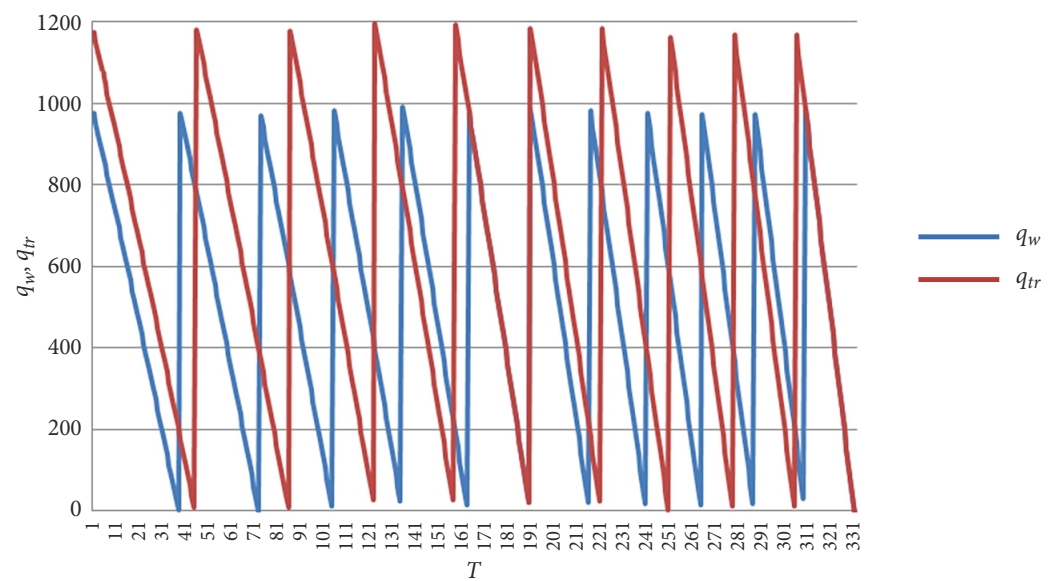

Figure 8. Dynamics of movement of goods in stock according to model (22) in the case of an increasing linear trend of daily demand under the condition of a constant order quantity (source: compiled by the authors according to the model)

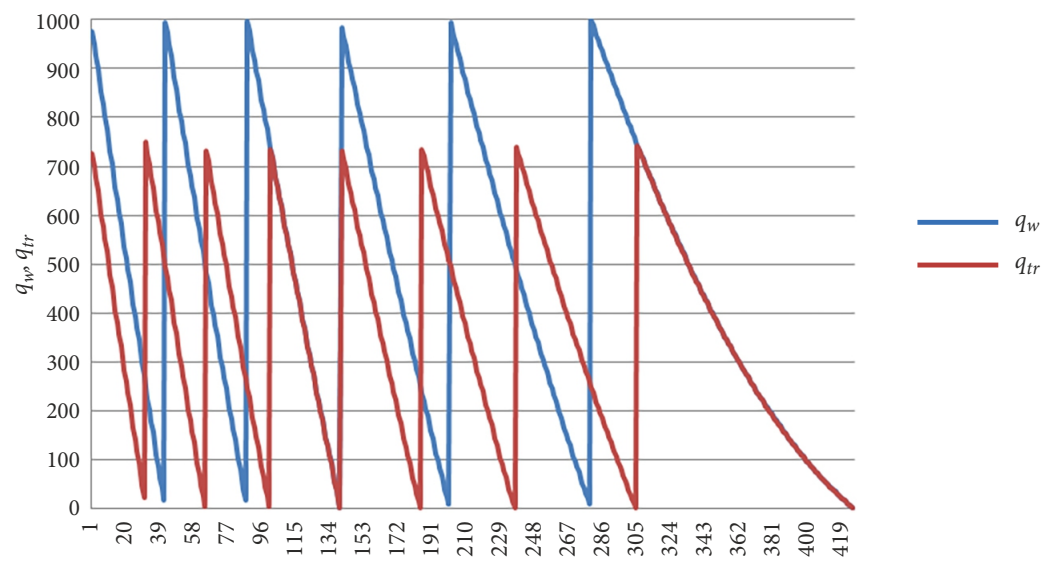

Figure 9. Dynamics of movement of goods in stock according to model (22) in the case of a decreasing linear trend of daily demand under the condition of a constant order quantity $q_{W}$ (source: compiled by the authors according to the model)

Application of the EOQ model at the beginning of each "delivery-storage" cycle starts with calculation of the $q_{W i}$ order quantity using the Wilson formula (formula 2) with the already known daily demand $\mu_{i}$ at the beginning of the $i$-th cycle and bringing the goods as inventory depletes through the actual time $t_{S i}$. This leads to an increase in total costs compared with the case of applying a model with a trend (formula 22), however, to a reduction in costs compared with the previous decision-making option. At the same time we get no delivery plan. Comparative plans of logistics processes are presented in Figures 10, 11.

The economic effect (benefit) $\left(\Delta T C=T C\left(q_{w}\right)-T C\left(q_{t r}\right)\right)$ on the use of the inventory management model with the trend in (22) depends on many factors and combinations of parameters of the logistic process. Although the total cost function has a kink on the domain (Figure 12), the function becomes inelastic in the area around its minimum (Figure 13). 


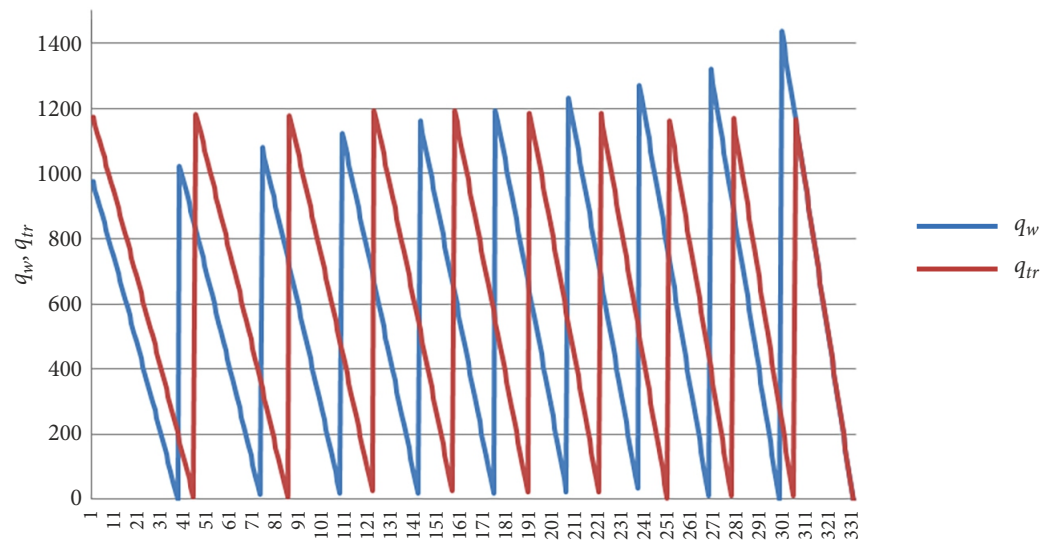

$T$

Figure 10. Dynamics of movement of goods in stock according to model (22) in the case of an increasing linear trend of daily demand under the condition of nonpermanent order quantity $q_{W}$ (determined by the Wilson model (2)) and $q_{t r}$ (the optimal value in models with the trend (27)) (source: compiled by the authors according to the model)

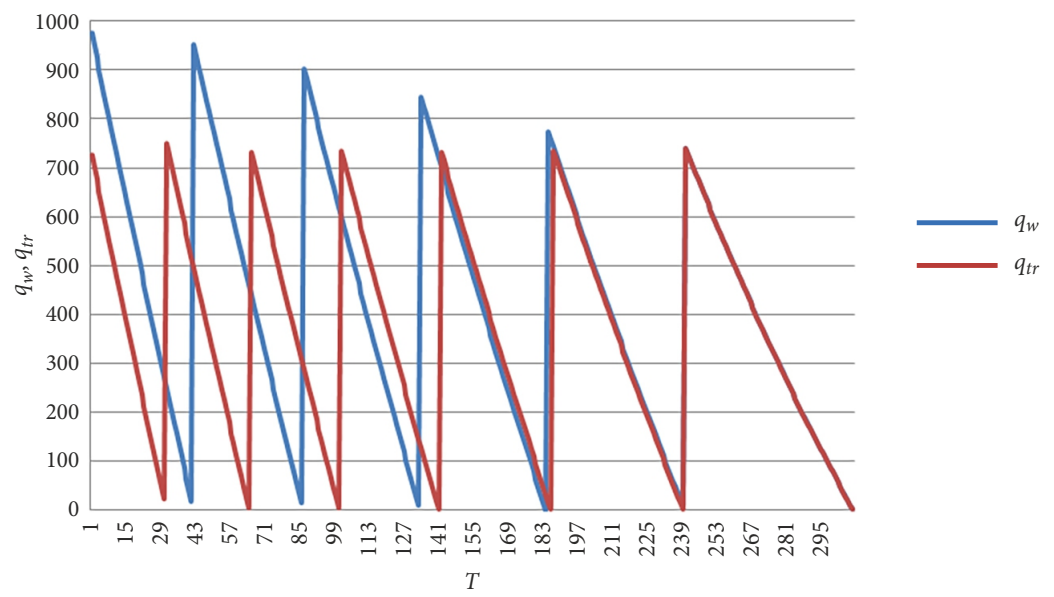

Figure 11. Dynamics of movement of goods in stock according to model (22) in the case of a decreasing linear trend of daily demand under the condition of nonpermanent order quantity $q_{W}$ (determined by the Wilson model (2)) and $q_{t r}$ (the optimal value in models with the trend (27)) (source: compiled by the authors according to the model)

The greater the daily change in daily demand $|\omega|$ and / or the longer the planning period $T$, the greater the average daily demand for the period $T \mu+\frac{1}{2} \omega(T-1)$ differs from the initial $\mu$. Consequently, the greater the value of the optimal volume of delivery $q_{t r}$ in (27) differs from the volume of delivery $q_{W}$ in (2), the greater the economic effect (benefit). It also follows from the form of the function (22) that the smaller the ratio of the cost of the order $p q$ to the cost of delivery $c_{S}$, the higher the economic effect (benefit).

Further on, let us consider a model example with the following parameters of the logistic process: $c_{\mathrm{s}}=400 \mathrm{EUR} ; p=20 \mathrm{EUR} ; r=0.001 ; \mu=25$ units/day; $\omega=0.066 ; T=333$ days. 


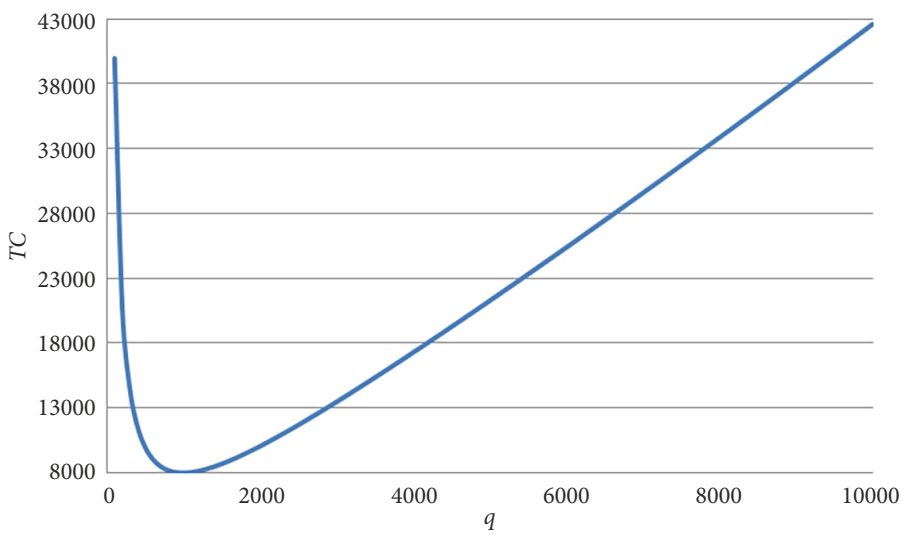

Figure 12. The total cost function (source: compiled by the authors according to the model)

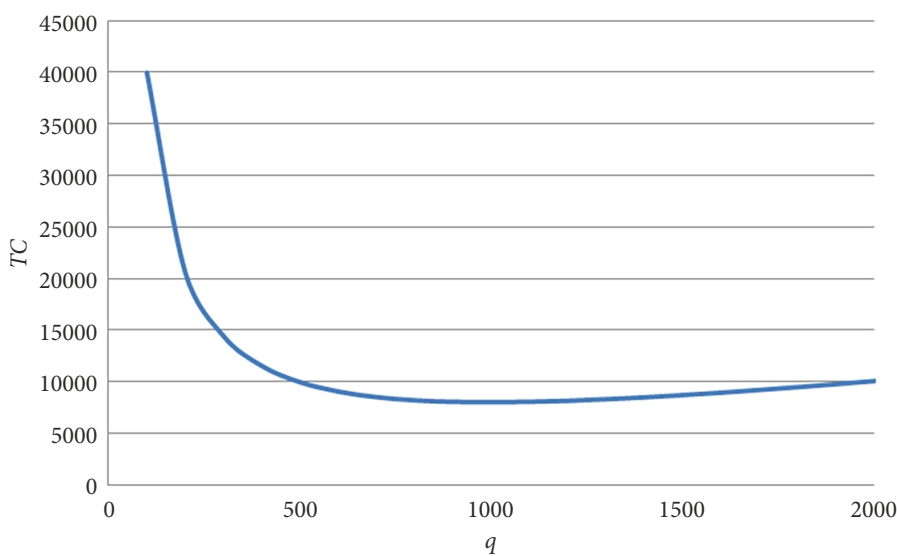

Figure 13. A minimum of the cost function (source: compiled by the authors according to the model)

The volume of the order by the formula Wilson: $q_{W}=\sqrt{\frac{2^{\star} 400^{\star} 25}{0,001^{\star} 20}}=1000$ units. After 333 days, daily demand will be equal to $25+0.066^{\star} 332=47$ units/day. The growth rate of daily demand is $47 / 25^{\star} 100 \%=188 \%$, the increment rate, respectively, $88 \%$. At the same time, the average daily demand for 333 days is 36 units/day, which is $36 / 25=1.44$ times more than the initial daily demand.The optimal order quantity is: $q_{t r}=\sqrt{1,44} q_{W}=1200$ units. Consequently, the growth of demand for 333 days by 1.88 times led to an increase in the optimal order volume of only 1.2 times. Total costs for the delivery and storage of goods for 333 days in quantities of 1,000 units and 1,200 units equal to $T C\left(q_{W}=1000\right)=9861$ EUR and TC $\left(q_{t r}=1200\right)=9744$ EUR, which corresponds to $1.2 \%$ savings.

In case when $\omega=0.376, T=400$ days, the daily demand after 400 days, will be equal to $25+$ $0.376 * 399=175$ units/day. The growth rate of daily demand is $175 / 25 * 100 \%=700 \%$, the increment rate, respectively, $600 \%$. At the same time, the average daily demand for 400 days 
is 100 units/day, which is $100 / 25=4$ times the initial daily demand. The optimal order quantity is: $q_{t r}=\sqrt{4} \mathrm{q}_{\mathrm{W}}=2000$ units. Consequently 7 times increase in demand for 400 days resulted in an increase in the optimum order size only 2 -fold. The total cost of delivery and storage of goods for 400 days when ordering in batches of 1000 units and 2000 units equal: to TC $\left(q_{W}=1000\right)=23325$ EUR and TC $\left(q_{t r}=2000\right)=19152$ EUR, which corresponds to $21.8 \%$ of the savings.

\section{Conclusions}

A big variety of EOQ models are being presented in economic literature, but as all it is being based either on Harris, Markov or Wilson's formulation, all it inherited the same drawbacks fixed constant demand and known in advance or at least predictable reorder time. Although these shortcomings did not make an influence in early applications of these models in practice, especially in production sector, there demand always exceeded supply, thus making it predictable, practical implementation of these models came to a halt and received a wide critics when it were to be applied in a retail business, especially ones, selling perishable goods. In the inventory management models, based on Wilson's formulation, the fundamental drawbacks appear, that are based on the main rationale of a formula, so they are hard to avoid, such as equality of time between orders and constant daily demand. It diminishes its practical value, especially in retail business; there above mentioned shortcomings prove crucial.

Thus we proved that the Wilson's model could be modified so that it remained valid if the daily number of orders decreased or increased over time. It was also proved that the modified Wilson model will be valid in the case of an increasing or decreasing linear trend of daily demand, subject to constant time between orders, as well as subject to constant overall order size. All these modifications allow a much wider use of the model in practice, as main barriers for its application in retail have been eradicated. Validation of the modified Wilson's model is proved by optimal solutions of solving systems of nonlinear equations and by decomposing the system's functions of Maclaurin series to the second degree. Thus, different variants of the approximate optimal solution of the Wilson model were obtained.

From a practical point of view, our proposed model generate a substantial economic effect (the savings exceed the costs of collecting, analyzing and processing additional information) when a particular conditions appear: a significant changes in consumer demand is being noticed and (or) a long period of planning the logistics process must be ensured. At the same time, in any case, building a model of inventory management with the trend it allows to generate an optimal plan for the functioning of the logistics process (to determine the optimal order sizes and intervals between orders), which allows integrating this procedure into other logistics processes, minimizing possible unforeseen expenses.

\section{Acknowledgements}

This work was supported by the National Natural Science of China (No. 71671165), National Statistical Science Research Project (No. 2018LY80), and First Class Discipline of Zhejiang A (Zhejiang Gongshang University - Statistics). 


\section{References}

Aguirregabiria, V., \& Vicentini, G. (2016). Dynamic spatial competition between multi-store retailers. The Journal of Industrial Economics, 64(4), 710-754. https://doi.org/10.1111/joie.12112

Battini, D., Persona, A., \& Sgarbossa, F. (2014). A sustainable EOQ model: theoretical formulation and applications. International Journal of Production Economics, 149, 145-153. https://doi.org/10.1016/j.ijpe.2013.06.026

Bendoly, E., Craig, N., \& DeHoratius, N. (2018). Consistency and recovery in retail supply chains. Journal of Business Logistics, 39(1), 26-37. https://doi.org/10.1111/jbl.12174

Beyer, W. H. (Ed.). (1987). CRC standard mathematical tables (28th ed., pp. 299-300). Boca Raton, FL: CRC Press.

Beyer, D., Cheng, F., Sethi, S. P., \& Taksar, M. (2010). Markovian demand inventory models. New York: Springer. https://doi.org/10.1007/978-0-387-71604-6

Boute, R. N., Disney, S. M., Lambrecht, M. R., \& Van Houdt, B. (2007). An integrated production and inventory model to dampen upstream demand variability in the supply chain. European Journal of Operational Research, 178(1), 121-142. https://doi.org/10.1016/j.ejor.2006.01.023

Broyles, J. R., Cochran, J. K., \& Montgomery, D. C. (2010). A statistical Markov chain approximation of transient hospital inpatient inventory. European Journal of Operational Research, 207(3), 1645-1657. https://doi.org/10.1016/j.ejor.2010.06.021

Budd, J. K., \& Taylor, P. G. (2019). Bounds for the solution to the single-period inventory model with compound renewal process input: An application to setting credit card limits. European Journal of Operational Research, 274(3), 1012-1018. https://doi.org/10.1016/j.ejor.2018.11.022

Cárdenas-Barrón, L. E., Chung, K. J., \& Treviño-Garza, G. (2014). Celebrating a century of the economic order quantity model in honor of Ford Whitman Harris. International Journal of Production Economics, 155, 1-7. https://doi.org/10.1016/j.ijpe.2014.07.002

Chen, X., Wang, X., \& Chan, H. K. (2017). Manufacturer and retailer coordination for environmental and economic competitiveness: A power perspective. Transportation Research Part E: Logistics and Transportation Review, 97, 268-281. https://doi.org/10.1016/j.tre.2016.11.007

Crist, E., Mora, C., \& Engelman, R. (2017). The interaction of human population, food production, and biodiversity protection. Science, 356(6335), 260-264. https://doi.org/10.1126/science.aal2011

De Matteis, J. J., \& Mendoza, A. G. (1968). An economic lot-sizing technique. IBM Systems Journal, 7 , 30-46. https://doi.org/10.1147/sj.71.0030

De, S. K., \& Sana, S. S. (2014). A multi-periods production-inventory model with capacity constraints for multi-manufacturers - A global optimality in intuitionistic fuzzy environment. Applied Mathematics and Computation, 242, 825-841. https://doi.org/10.1016/j.amc.2014.06.075

Dubelaar, C., Chow, G., \& Larson, P. D. (2001). Relationships between inventory, sales and service in a retail chain store operation. International Journal of Physical Distribution \& Logistics Management, 31(2), 96-108. https://doi.org/10.1108/09600030110387480

Durach, C. F., \& Nitsche, B. (2016). Successfully managing challenges in German-Chinese logistics networks (Vol. 6). Universitätsverlag der TU Berlin.

Fernie, J., \& Sparks, L. (Eds.). (2018). Logistics and retail management: emerging issues and new challenges in the retail supply chain. Kogan Page Publishers.

Feng, J., Zhao, L., Jia, H., \& Shao, S. (2019). Silk Road Economic Belt strategy and industrial totalfactor productivity: Evidence from Chinese industries. Management of Environmental Quality: An International Journal, 30(1), 260-282. https://doi.org/10.1108/MEQ-06-2018-0109

Fleisch, E., \& Tellkamp, C. (2005). Inventory inaccuracy and supply chain performance: a simulation study of a retail supply chain. International Journal of Production Economics, 95(3), 373-385.

https://doi.org/10.1016/j.ijpe.2004.02.003 
Ganesan, S., George, M., Jap, S., Palmatier, R. W., \& Weitz, B. (2009). Supply chain management and retailer performance: emerging trends, issues, and implications for research and practice. Journal of Retailing, 85(1), 84-94. https://doi.org/10.1016/j.jretai.2008.12.001

Goldman, A., Ramaswami, S., \& Krider, R. E. (2002). Barriers to the advancement of modern food retail formats: theory and measurement. Journal of Retailing, 78(4), 281-295.

https://doi.org/10.1016/S0022-4359(02)00098-2

Greenstone, M. (2017). The continuing impact of Sherwin Rosen's "Hedonic prices and implicit markets: product differentiation in pure competition". Journal of Political Economy, 125(6), 1891-1902. https://doi.org/10.1086/694645

Gustafsson, K., Jönson, G., Smith, D., \& Sparks, L. (2006). Retailing logistics and fresh food packaging: managing change in the supply chain. Kogan Page Publishers.

Hackl, P., Scharitzer, D., \& Zuba, R. (2000). Customer satisfaction in the Austrian food retail market. Total Quality Management, 11(7), 999-1006. https://doi.org/10.1080/09544120050135524

Harris, I., Naim, M., Palmer, A., Potter, A., \& Mumford, C. (2011). Assessing the impact of cost optimization based on infrastructure modelling on $\mathrm{CO} 2$ emissions. International Journal of Production Economics, 131(1), 313-321. https://doi.org/10.1016/j.ijpe.2010.03.005

Hayakawa, H., \& Venieris, Y. (2016). Consumer interdependence via reference groups. In Behavioral Interactions, Markets, and Economic Dynamics (pp. 81-99). Tokyo: Springer. https://doi.org/10.1007/978-4-431-55501-8_3

Hinsley, A., Verissimo, D., \& Roberts, D. L. (2015). Heterogeneity in consumer preferences for orchids in international trade and the potential for the use of market research methods to study demand for wildlife. Biological Conservation, 190, 80-86. https://doi.org/10.1016/j.biocon.2015.05.010

Hosken, D. S., Olson, L. M., \& Smith, L. K. (2018). Do retail mergers affect competition? Evidence from grocery retailing. Journal of Economics \& Management Strategy, 27(1), 3-22. https://doi.org/10.1111/jems.12218

Isotupa, K. S. (2006). An (s, Q) Markovian inventory system with lost sales and two demand classes. Mathematical and Computer Modelling, 43(7-8), 687-694. https://doi.org/10.1016/j.mcm.2005.09.027

Karimi, B., Ghomi, S. F., \& Wilson, J. M. (2003). The capacitated lot sizing problem: a review of models and algorithms. Omega, 31(5), 365-378. https://doi.org/10.1016/S0305-0483(03)00059-8

Khmelnitsky, E., \& Singer, G. (2015). An optimal inventory management problem with reputationdependent demand. Annals of Operations Research, 231(1), 305-316. https://doi.org/10.1007/s10479-014-1600-z

Konstantaras, I., Skouri, K., \& Lagodimos, A. G. (2019). EOQ with independent endogenous supply disruptions. Omega, 83, 96-106. https://doi.org/10.1016/j.omega.2018.02.006

Liberopoulos, G., Tsikis, I., \& Delikouras, S. (2010). Backorder penalty cost coefficient "b": What could it be? International Journal of Production Economics, 123(1), 166-178.

https://doi.org/10.1016/j.ijpe.2009.07.015

Liu, M., Feng, M., \& Wong, C. Y. (2014). Flexible service policies for a Markov inventory system with two demand classes. International Journal of Production Economics, 151, 180-185. https://doi.org/10.1016/j.ijpe.2013.10.010

Manna, A. K., Dey, J. K., \& Mondal, S. K. (2017). Imperfect production inventory model with production rate dependent defective rate and advertisement dependent demand. Computers \& Industrial Engineering, 104, 9-22. https://doi.org/10.1016/j.cie.2016.11.027

Minoux, M. (2018). Robust and stochastic multistage optimisation under Markovian uncertainty with applications to production/inventory problems. International Journal of Production Research, 56(12), 565-583. https://doi.org/10.1080/00207543.2017.1394597

Myerson, P. (2012). Lean supply chain and logistics management. New York, NY: McGraw-Hill. 
Nestorenko, O., Péliová, J., \& Nestorenko, T. (2017). Economic and mathematical models of inventory management with deficit and with proportional to waiting time the penal sanctions. Knowledge and skills for sustainable development: The role of Economics, Business, Management and Related Disciplines. In EDAMBA-2017. Conference Proceedings of International Scientific Conference for Doctoral Students and Post-Doctoral Scholars (pp. 351-359), 4-6 April 2017, University of Economics in Bratislava. Retrieved from https://edamba.euba.sk/www_write/files/archive/edamba2017proceedings.pdf

Nobil, A. H., \& Taleizadeh, A. A. (2016). A single machine EPQ inventory model for a multi-product imperfect production system with rework process and auction. International Journal of Advanced Logistics, 5(3-4), 141-152. https://doi.org/10.1080/2287108X.2016.1207975

Ortega, D. L., Wang, H. H., Wu, L., \& Hong, S. J. (2015). Retail channel and consumer demand for food quality in China. China Economic Review, 36, 359-366. https://doi.org/10.1016/j.chieco.2015.04.005

Ortolani, C., Persona, A., \& Sgarbossa, F. (2011). External cost effects and freight modal choice: research and application. International Journal of Logistics Research and Applications, 14(3), 199-220. https://doi.org/10.1080/13675567.2011.609536

Paul, S. K., Sarker, R., \& Essam, D. (2018). A reactive mitigation approach for managing supply disruption in a three-tier supply chain. Journal of Intelligent Manufacturing, 29(7), 1581-1597. https://doi.org/10.1007/s10845-016-1200-7

Quesada-Pineda, H. J. (2008). Lean inventory management in the wood products industry: Examples and applications. Retrieved from https://www.pubs.ext.vt.edu/420/420-148/420-148.html

Rong, A., Akkerman, R., \& Grunow, M. (2011). An optimization approach for managing fresh food quality throughout the supply chain. International Journal of Production Economics, 131(1), 421429. https://doi.org/10.1016/j.ijpe.2009.11.026

Rostamzadeh, R., Esmaeili, A., Shahriyari Nia, A., Saparauskas, J., \& Keshavarz Ghorabaee, M. K. (2017). A fuzzy ARAS method for supply chain management performance measurement in SMEs under uncertainty. Transformations in Business \& Economics, 16(2A), 319-348.

Sana, S. S. (2011). Price-sensitive demand for perishable items-an EOQ model. Applied Mathematics and Computation, 217(13), 6248-6259. https://doi.org/10.1016/j.amc.2010.12.113

Sarkar, B. (2013). A production-inventory model with probabilistic deterioration in two-echelon supply chain management. Applied Mathematical Modelling, 37(5), 3138-3151. https://doi.org/10.1016/j.apm.2012.07.026

Schwartz, B. L. (1970). Optimal inventory policies in perturbed demand models. Management Science, 16(8), B509-B518. https://doi.org/10.1287/mnsc.16.8.B509

Schwartz, J. D., Wang, W., \& Rivera, D. E. (2006). Simulation-based optimization of process control policies for inventory management in supply chains. Automatica, 42(8), 1311-1320. https://doi.org/10.1016/j.automatica.2006.03.019

Silver, E. A., \& Meal, H. C. (1973). A heuristic for selecting lot size quantities for the case of a deterministic time - varying demand rate and discrete opportunities for replenishment. Production and Inventory Management, 14(2), 64-74.

Slesarenko, A., \& Nestorenko, A. (2014). Development of analytical models of optimizing an enterprise's logistics information system supplies. Eastern-European Journal of Enterprise Technologies, 5(3(71)), 61-66. https://doi.org/10.15587/1729-4061.2014.27746

Song, M. L., Cui, X., \& Wang, S. H. (2018). Simulation of land green supply chain based on system dynamics and policy optimization. International Journal of Production Economics. https://doi.org/10.1016/j.ijpe.2018.08.021

Soto-Silva, W. E., Nadal-Roig, E., González-Araya, M. C., \& Pla-Aragones, L. M. (2016). Operational research models applied to the fresh fruit supply chain. European Journal of Operational Research, 251(2), 345-355. https://doi.org/10.1016/j.ejor.2015.08.046 
Sterligova, A. N. (2005). O suguboj praktichnosti formuly Vil'sona. Logistika \& sistema 4, 42-52. (in Russian).

Taleizadeh, A. A. (2017). Lot-sizing model with advance payment pricing and disruption in supply under planned partial backordering. International Transactions in Operational Research, 24(4), 783800. https://doi.org/10.1111/itor.12297

Tamjidzad, S., \& Mirmohammadi, S. H. (2017). Optimal (r, Q) policy in a stochastic inventory system with limited resource under incremental quantity discount. Computers \& Industrial Engineering, 103, 59-69. https://doi.org/10.1016/j.cie.2016.11.012

Tasdemir, C., \& Hiziroglu, S. (2019). Achieving cost efficiency through increased inventory leanness: Evidences from oriented strand board (OSB) industry. International Journal of Production Economics, 208, 412-433. https://doi.org/10.1016/j.ijpe.2018.12.017

Wagner, J., \& Benoit, S. (2015). Creating value in retail buyer-vendor relationships: A service-centered model. Industrial Marketing Management, 44, 166-179.

https://doi.org/10.1016/j.indmarman.2014.10.013

Wahab, M. I. M., Mamum, S. M. H., \& Ongkunaruk, P. (2011). EOQ models for a coordinated two-level international supply chain considering imperfect items and environmental impact. International Journal Production Economics, 134, 151-158. https://doi.org/10.1016/j.ijpe.2011.06.008

Wilson, R. H. (1934). A scientific routine for stock control. Harvard Business Review, 13(1), 116-129.

Yao, X., Huang, R., Song, M., \& Mishra, N. (2018). Pre-positioning inventory and service outsourcing of relief material supply chain. International Journal of Production Research, 56(21), 6859-6871. https://doi.org/10.1080/00207543.2018.1495853

Yin, K. K., Liu, H., \& Johnson, N. E. (2002). Markovian inventory policy with application to the paper industry. Computers \& Chemical Engineering, 26(10), 1399-1413. https://doi.org/10.1016/S0098-1354(02)00113-8

Yuan, B. L., \& Zhang, K. (2017). Can environmental regulation promote industrial innovation and productivity? Based on the strong and weak porter hypothesis. Chinese Journal of Population, Resources and Environment, 15(4), 322-336. https://doi.org/10.1080/10042857.2017.1416042 